\title{
Effectiveness of the Compound Chlorpyrifos+ Cypermethrin+Citronellal Against Alphitobius Diaperinus. Laboratory Analysis and Residue Determination in Carcasses
}

\begin{tabular}{l} 
שuthor(s) \\
\hline Silva $\mathrm{GS}^{1 *}$ \\
Michels $\mathrm{MG}^{2}$ \\
Toma $\mathrm{SB}^{2}$ \\
Terra $\mathrm{FE}^{2}$ \\
Soares $\mathrm{VE}^{3}$ \\
Costa $\mathrm{J}^{3}$ \\
1 Pólo Regional do Noroeste Paulista/Paulist \\
Agency of Agribusiness Tecnology - APTA/ \\
SAA. \\
2 Ouro Fino Animal Health Ltda. \\
3 CPPAR - Research Center of Animal Sanity/ \\
FCAV/UNESP.
\end{tabular}

\section{Mail Address}

\section{GS Sila}

Pólo Regional do Noroeste Paulista/APTA/SAA Postal Code Box 61

15.500-970. Votuporanga, SP, Brazil.

Phone: 1734222423

Fax: $\quad 1734218148$

E-mail: giane@aptaregional.sp.gov.br

\section{Keywords}

Alphitobius diaperinus, broiler, Cypermethrin +Chlorpyrifos+Citronellal, residue.

\section{ABSTRACT}

Effectiveness, biological security and the absence of residues in meat and/or eggs must be considered when recommending options for the control A/phitobius diaperinus in poultry production environments. This research study evaluated the effectiveness of cypermethrin+ chlorpyrifos+citronellal in the control of $A$. diaperinus, including analysis for the presence of residues of this compound in poultry carcasses (experimental farm). Two studies were carried out under laboratory conditions. One used paper filters a four dilutions of the compound, and the other used a container including with pulverized broiler litter and the compound. The analysis of carcasses for residues was conducted in broilers that raised in a broiler house treated (floor and/or litter) with the compound at a dilution of 1:800. Birds were regularly sacrificed, submitted to necropsy, and liver, muscle and fat fragments were collected. Gas chromatography was used to identify the possible presence of any chemical residue in these samples. High effectiveness rates against $A$. diaperinus were observed in the two laboratory studies, as well as the absence of residues in the carcasses. This compound, used in the studied concentrations, can be recommended as a valuable alternative for the control and treatment of $A$. diaperinus.

\section{INTRODUCTION}

Alphitobius diaperinus, commonly called darkling beetle, is very important in poultry production, particularly when it affects broilers or layers. This beetle is a reservoir and vector of several significant pathogens in poultry production, such as Eimeria, Escherichia, Salmonella and Aspergillus, as well as viruses that cause Marek, Infectious Bursal and Newcastle diseases, as well as Avian Influenza (Safrit \& Axtell, 1984). It may also act as an intermediate host of cestodes (Arends, 1987).

Therefore, the use of integrated pest management and chemical control of the darkling beetle is recommended, providing benefits, such as lowering costs and health risks, and maximizing productivity. Although scientific studies advocate different chemical groups for control of darkling beetles, such as pyrethroids, organophosphates, macrocyclic lactones, organochlorines, and carbamates (Miller, 1990; Morales, 1991; Gomes, 2000; Souza, 2005), resistance to some groups of chemicals, including fenitrothion and ciflutrin, have been recorded (Lambkin, 2001).

In addition to effectiveness and biological security, the absence of residues in meat and/or eggs, and the low interference in poultry metabolism are very important aspects to consider when recommending new alternatives for beetle control. Chlorpyrifos is an organophosphate, which mode of action is the inhibition of insect acetylcholinesterase, interfering in neuromuscular transmission with consequent parasite death. Belonging to pyrethroid group, cypermethrin inhibits sodium and 
Silva GS, Michels MG, Toma SB, Terra FE, Soares VE, Costa AJ
Effectiveness of the Compound Chlorpyrifos+ Cypermethrin+Citronellal Against Alphitobius Diaperinus. Laboratory Analysis and Residue Determination in Carcasses potassium transport in the parasite's nervous system and has been widely used against ectoparasites in different animal species (Baldan et al., 1999). The repellent effect of substances extracted from vegetable sources has been extensively explored. Citronella shows ectoparasiticide effectiveness (Martins, 2006). The use of combined substances seems promising in the control of parasites, as the different chemical groups included have different modes of action. These combinations therefore may present better results against parasites, also when these are resistant to individual substances. The combination cypermethrin+chlorpyrifos+citronellal was successful to control ectoparasites (Alves-Branco, 2005).

This study evaluated the effectiveness of cypermethrin+chlorpyrifos+citronellal combination against $A$. diaperinus, in the laboratory (using Petri dishes and litter), and the possible presence of residues of this compound in poultry carcasses.

\section{MATERIALS AND METHODS}

\section{Effectiveness against $A$. diaperinus -- Petri Dishes}

A. diaperinus specimens were collected in a naturally infested poultry farm, with no history of chemical treatments for at least three production cycles. Samples were submitted to the Artropodology Laboratory of the Animal Health Research Center of School of Agrarian and Veterinary Sciences of Universidade Estadual Paulista (CPPAR/FCAVJ/UNESP), where they were divided into groups of 10 individuals (larvae and adults), and daily observed for three days. After this period, paper filters $(90 \mathrm{~mm})$, saturated with the cypermethrin+chlorpyrifos+citronellal formulation, were applied to the Petri dishes, as described in Table 1. After 30 minutes, darkling beetles (total: 100 adults or 100 larvae/group) were placed on the treated paper filters in the respective dishes. Three and 24 hours posttreatment (HPT), the number and the percentage of live and dead adults and larvae were calculated, and used to indicate treatment effectiveness.

The experimental design applied was Split Plot in Time, with products and controls as the 2 main treatments (10 replicates), and observation days as secondary treatments (Banzatto \& Kronka, 1989).

\section{Effectiveness against $A$. diaperinus - Litter}

Litter (peanut hulls) was obtained from a commercial broiler farm (14-day-old birds), with no chemical treatment history. Litter was placed in plastic containers at 4-cm depth, and $A$. diaperinus adults and larvae (ten replicates/group, total of 100 adults and 100 larvae/ group) were placed in each container. Containers were randomly designated to 5 experimental groups: pulverization $\left(1 \mathrm{~L} / 1,2 \mathrm{~m}^{2}\right)$ of 4 dilutions of the insecticide combination (GI-1:400; GII-1:600; GIII-1:800; GIV$1: 1000)$, and pulverization with water (control group).

One, three, seven and fourteen days post-treatment (DPT), the contents of each container were removed and the number of live and dead adults and larvae was counted.

Treatment effectiveness was considered as the percentage of live adults and larvae in each evaluated period.

The design was in fraction subdivided in time ("split plot in time") and the F-test and Tukey's test were applied.

\section{Carcass Residues}

This trial was carried out at CPPAR experimental farm, using 12 boxes $\left(3,67 \mathrm{~m}^{2} / \mathrm{box}\right)$. Three boxes were separated from the others by masonry wall, where the control group was raised. Each box was equipped with heating, and individual drinkers and feeders.

After cleaning and disinfection, using only flamethrower and water, the floor and internal box walls were painted with whitewash.

Insecticide combination was applied according to the experimental groups shown in Table 2 on same day for all the treatments, 48 hours after whitewashing. Litter (rice husks) was evenly distributed (10 cm height).

Forty eight hours after insecticide application, in all treatments, 30 male Cobb broiler chicks were randomly housed in the boxes (30 birds/replicate). Birds were offered water and feed ad libitum. Feed was formulated to meet broilers nutritional requirements.

Additionally, in order to evaluate toxicity and product residue in carcasses, three 10-day-old birds were forced-fed $A$. diaperinus (10 adults and 10 larvae/bird) treated with the product. Beetles were immersed for 5 minutes in the insecticide solution prepared at a 1:800 dilution.

\section{Birds were daily observed for possible clinical signs caused by the treatments.}

At the established experimental periods $(7,14$ and 21 days after placement), 10 birds from each experimental group were randomly chosen (03 birds of two replicates and 04 birds of one replicate/ 
Silva GS, Michels MG, Toma SB, Terra FE, Soares VE, Costa AJ
Effectiveness of the Compound Chlorpyrifos+ Cypermethrin+Citronellal Against Alphitobius Diaperinus. Laboratory Analysis and Residue Determination in Carcasses experimental) were sacrificed and submitted to necropsy. Liver, muscle sections (breast, thigh and upper thigh) and fat were collected from each bird and submitted to the Laboratory of Pesticide Residues and Chromatographic Analysis of Agricultural Zoology and Entomology Department of ESALQ/USP for analysis of cypermethrin, 3-phenoxybenzoic acid, chlorpyrifos, chlorpyrifos-oxon, 3,5,6-trichloro-2-pyridinol residues. Quantitative determination was performed by gas chromatography, using a chromatograph equipped with mass-selective detector (GC/MSD), with quantification limit of $0.05 \mathrm{mg} / \mathrm{kg}$, according to the methods described by Argauer et al (1997) and Juhler (1996).

\section{RESULTS}

\section{Effectiveness against $A$. diaperinus - Petri Dishes}

A. diaperinus individuals in the control group (GVControl) remained alive during the entire experimental period (Figure 1). On the other hand, all beetles treated with the insecticide combination (GI to GIV- dilutions of $1: 400 ; 1: 600 ; 1: 800$ and $1: 1000$, respectively) did not move, being dorsally recumbent already at $3 \mathrm{HPT}$. The few darkling beetles that showed, while in dorsal recumbency, some leg and/or antenna movements, did not move when placed in ventral recumbency.

In the second evaluation, made at 24 HPT, this diagnosis was confirmed, which it allows us to infer that the Cypermethrin+Chlorpyrifos+Citronellal association was $100 \%$ effective against $A$. diaperinus larvae and adults.

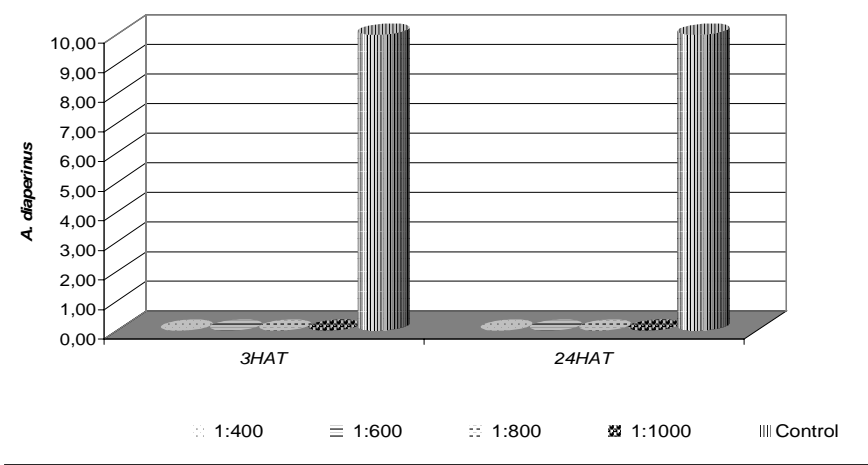

Figure 1 - Means of $A$. diaperinus (adults and larvaes) alives of the control and treated groups. CPPAR/FCAV/UNESP.

\section{Effectiveness against $A$. diaperinus - Litter}

When the study was carried out with litter, $A$. diaperinus adults belonging to control group were alive, and normally moving during the entire experimental period, except for one of the 100 darkling beetles of this group. Similar behavior was observed with larvae of this group up to 7 DPT (only five larvae died during this period). On 14 DPT, the presence of pupaes was detected in all control group replicates of, which explains the lower number of larvae counted. Adults developed from these pupaes, confirming that experimental conditions were adequate.

Still in the control group, the presence of a large number of first-stage larvae was observed on 7 DPT, originated from the laying adults.

It must be stressed that no pupae or larvae were observed in the groups treated with the different insecticide dilution, proving, therefore, that the products acts by interrupting the biological cycle of $A$. diaperinus.

The lowest dilution (1:400) of the insecticide combination showed $100 \%$ effectiveness against $A$. diaperinus adults and larvae since the first evaluation after treatment (Figures 2 and 3). Similarly, in the 1:600 dilution, the product showed $100 \%$ effectiveness against larvae in the first evaluation, whereas this percentage was reached only on 7 DPT in adults.

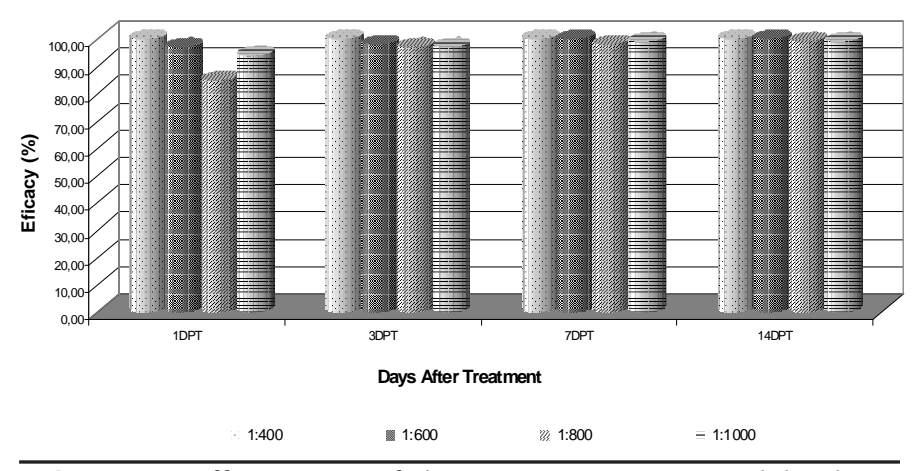

Figure 2 - Effectiveness of the treatments against Alphitobius diaperinus adults. CPPAR/FCAV/UNESP.Jaboticabal, SP, Brazil.

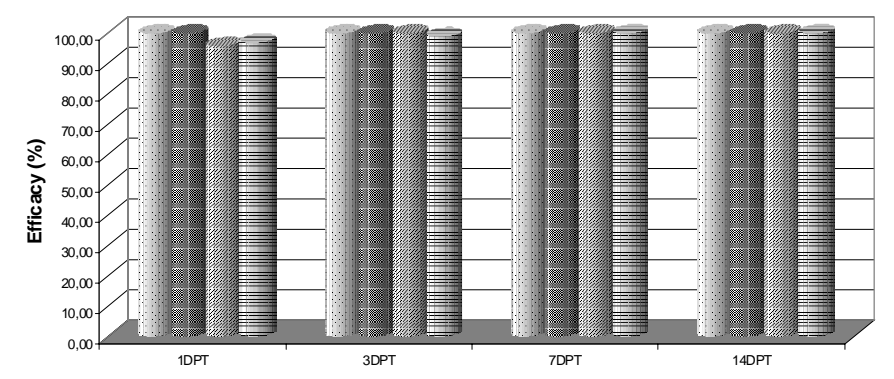

Days After Treatment

$\therefore 1: 400 \quad$ : $1: 600 \quad \equiv 1: 1000$

Figure 3 - Effectiveness of the treatments against lavaes of Alphitobius diaperinus. CPPAR/FCAV/UNESP. Jaboticabal, SP, Brazil. 
Silva GS, Michels MG, Toma SB, Terra FE, Soares VE, Costa AJ
Effectiveness of the Compound Chlorpyrifos+ Cypermethrin+Citronellal Against Alphitobius Diaperinus. Laboratory Analysis and Residue Determination in Carcasses
Precisely on 1 DPT, there was statistical difference $(P<0.05)$ in darkling beetle adult counts between the 1:800 dilution as compared to the other treatment groups. On this day, this dilution showed the lowest efficacy $(84,85 \%)$.

However, statistical comparisons between treatments on the remaining evaluation days revealed significant differences $(\mathrm{P}<0.05)$ between the treated groups and the control group.

On the other evaluated days, all treatments were very effective (more than 96\%) against adults, with $1: 800$ and $1: 1000$ dilutions presenting $98.99 \%$ effectiveness against $A$. diaperinus adults on 14 DPT and 7 DPT, respectively. As to larvae, the 1:800 dilution was $100 \%$ effective on 3 DPT, and the highest dilution (1:1000) on 7 DPT.

\section{Carcass Residue}

No clinical signs caused by insecticide treatment were observed, including in birds that were forcedfed with darkling beetles immersed in the product.

Results relative to carcass residues $(\mathrm{mg} / \mathrm{kg})$ of cypermethrin, chlorpyrifos, 3-phenoxybenzoic acid, chlorpyrifos-oxon, 3,5,6-trichloro-2-pyridinol presented levels lower than the limit of detection of the adopted method, i.e., lower than $0.05 \mathrm{mg} / \mathrm{kg}$ in all evaluated samples, including those collected from the three birds that were forced-fed with $A$. diaperinus immersed in the product.

\section{DISCUSSION AND CONCLUSION}

The results of the Petri Dishes study allow inferring that the compound Cypermethrin+Chlorpyrifos+ Citronellal was $100 \%$ effective against $A$. diaperinus larvae and adults. These results demonstrate the excellent performance of drug combinations in parasite control, including active ingredients extracted from plant sources.

According Baldani et al. (1999), the mode of action of chlorpyrifos is acetyl cholinesterase inhibition, whereas cypermethrin acts by inhibiting sodium and potassium transportation in the parasite nervous system.

Alves-Branco et al. (2005) report 100\% effectiveness of the same association in the control of the lice Damalia ovis in naturally infested sheep. In the present study, effectiveness rates against $A$. diaperinus were higher, including at the highest dilution applied (1:800). These findings demonstrate that darkling beetle chemical control can be recommended and used to reduce its population, allowing the reduction of costs and health risks, and improving productivity of poultry farms.
The absence of residues in meat and/or eggs, and the low interference in poultry metabolism are important factors to consider when recommending and selecting new control alternatives. The present study demonstrated that the evaluated insecticide combination is clinically safe, and does not cause meat residues.

The high effectiveness obtained with of Cypermethrin+Chlorpyrifos+Citronellal in the applied concentrations and modes of use and the absence of residues in meat, evidence that this combination is an important alternative for the control of $A$. diaperinus.

\section{REFERENCES}

Alves-Branco FPJ, Sapper MFM, Toma SB, Cassol DMS, Alves-Branco, LRF, Gomes TM. Eficácia da associação Cipermetrina (15,0g), Clorpirifós $(25,0 \mathrm{~g})$ e Citronelal $(1,0 \mathrm{~g})$, aplicada sob as formas de imersão e solução aquosa (administrada dorsalmente), em ovinos da raça Corriedale, infestados pelo piolho Damalina ovis, no Rio Grande do Sul. A Hora Veterinária 2005; 24(144):29-34.

Arends JJ. Control, management of the litter beetle. Poultry Digest 1987; 44:172-6.

Baldani LA, Sousa RV, Miguel AG. Farmacologia dos principais antiparasitários de uso na medicina veterinária. Lavras: Universidade Federal de Lavras; 1999.

Gomes JPC. Controle de Alphitobius diaperinus (Panzer) (Coleoptera: Tenebrionidae) em aviários. Anais do Simpósio Brasil Sul de Avicultura; 2000 abr 5-6; Chapecó, Santa Catarina. Brasil.

Lambkin TA. Investigations into the management of the darkling beetle. Queensland: Rural Industries Research and Development Corporation; 2001. p.1-99.

Martins RM. Estudo "in vitro" da ação acaricida do óleo essencial da gramínea Citronela de Java (Cymbopogon winterianus Jowitt) no carrapato Boophilus microplus. Revista Brasileira de Plantas Medicinais 2006; 8(2):71-78.

Miller RW. Use of ivermectin to control the lesser mealworm (Coleoptera: Tenebrionidae) in a simulated poultry broiler house. Poultry Science 1990; 69(8):1281-84.

Morales A. Control químico del coleóptero Alphitobius diaperinus com Malathion, Carbaril y Dipterex en granjas avícolas. Revista Cubana de Ciencias Avícola1991;18:205-9.

Safrit RD, Axtell RC. Evaluations of sampling methods for darkling beetles (Alphitobius diaperinus) in the litter of turkey and broiler houses. Poultry Science 1984; 63:2368-75.

Souza LM. Avaliações experimentais do spinosad no controle do Alphitobius diaperinus (Coleoptera: Tenebrionidae). Ensaios in vitro e em sistemas de produção avícola [tese]. Jaboticabal: Universidade Estadual Paulista, Faculdade de Ciências Agrárias e Veterinárias; 2005. 